\title{
COMIDA DE ESTÁDIO: REFLEXÕES SOBRE O "TROPEIRÃO" E A SOCIABILIDADE NO “NOVO MINEIRÃO"
}

\author{
STADIUM FOOD: REFLECTIONS ON "TROPEIRÃO" BEANS AND \\ SOCIABILITY AT THE "NEW MINEIRÃO ARENA" C
}

COMIDAS DE ESTADIO: REFLEXIONES SOBRE EL "TROPEIRÃO" Y LA SOCIABILIDAD EN EL "NUEVO MINEIRÃO" C己

doi' https://doi.org/10.22456/1982-8918.98224

\footnotetext{
iD Leonardo Turchi Pacheco*<leonardoturchi@gmail.com>

(iD) Marina de Mattos Dantas ${ }^{* *}<$ marinamattos@gmail.com>

Adriano Lopes de Souza** <adriano.maceio@hotmail.com>

Silvio Ricardo da Silva** <prof.srs@gmail.com>

* Universidade Federal de Alfenas, Alfenas, MG, Brasil.

** Universidade Federal de Minas Gerais, Belo Horizonte, MG, Brasil.
}

\begin{abstract}
Resumo: O presente artigo analisa as mudanças na alimentação e nas formas de sociabilidade no "novo" Estádio Mineirão pela perspectiva de 266 torcedores do Clube Atlético Mineiro. Ademais, apresenta uma breve análise do perfil do público que frequentou o Estádio do Mineirão entre 2013 e 2015, fruto de pesquisa de campo na qual foram aplicados questionários e feitas observações no ambiente das arquibancadas. Verificou-se, na fala torcedora, incômodos com as alterações na alimentação e nas experiências que compunham a totalidade do espetáculo. Quanto ao perfil dos torcedores, observou-se o alto grau de escolaridade e empregabilidade, além de residirem em locais com elevado Índice de Desenvolvimento Humano Municipal (IDHM). Esse cenário trouxe consigo novas percepções sobre aparência do equipamento urbano e higiene alimentar, evidenciando um espaço de disputas pela alimentação dentro e fora do estádio e outras mudanças na sociabilidade torcedora.
\end{abstract}

Palavras chave: Futebol. Atividades de Lazer. Mudança social. Instalações esportivas e recreacionais.
Recebido em: 14/11/2019 Aprovado em: 01/06/2020 Publicado em: 30-07-2020

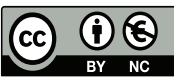

Este é um artigo publicado sob a licença Creative Commons atribuição Não Comercial 4.0 (CC BY-NC 4.0).

eISSN: 1982-8918 


\section{INTRODUÇÃO}

A escolha do Brasil como país-sede da $19^{a}$ edição da Copa do Mundo de Futebol Masculino, em 2014, trouxe consigo importantes transformações para o cenário futebolístico brasileiro, fundamentalmente, em função da importância desse megaevento na esfera esportiva mundial. Ainda que muitas vezes assumam um importante papel no desenvolvimento urbano, contribuindo para a geração de potenciais legados nas regiões onde são sediados, a ocorrência de eventos esportivos dessa magnitude exige grandes investimentos para a construção ou adequação de uma série de equipamentos, notadamente estádios de futebol e infraestrutura complementar (REIS; CABRAL, 2017).

Amiúde, diante das exigências quanto ao cumprimento das normativas (BOTTA; DELMONT; REDDY, 2011) apresentadas pela Fédération Internationale de Football Association (FIFA), frequentemente torna-se tão importante, quanto necessária, a participação de órgãos governamentais para garantir a exequibilidade da Copa do Mundo no país-sede. Nessa seara, Reis e Cabral (2017) destacam a necessidade de intervenções nos estádios brasileiros previstos para sediar os jogos da competição. Após a definição das 12 cidades-sede do torneio em maio de 2009, a disponibilização de estádios em padrões de excelência tornou-se uma demanda latente (REIS; CABRAL, 2017, p. 553).

O Estado esteve presente nas construções e/ou reformas de nove desses estádios colocados à disposição da FIFA para a Copa do Mundo, com destaque para a utilização das Parcerias Público-Privada (PPP), presentes em cinco dessas intervenções (REIS; CABRAL, 2017). De acordo com Cabral e Silva Jr. (2009), a PPP figura no rol de modalidades ${ }^{1}$ de provisão em que o compartilhamento de direitos de propriedade e dos direitos residuais de controle entre estatais e empresas privadas se fazem presentes. Nesse caso, a empresa privada assume a figura do agente, ou seja, aquele que recebe a incumbência de tomar decisões e de exercer os direitos residuais de controle durante o período de execução contratual (CABRAL; SILVA JR., 2009, p.42).

A cidade de Belo Horizonte esteve entre as cidades-sede. Para o evento, foi disponibilizado o Estádio Governador Magalhães Pinto, conhecido popularmente como "Mineirão". Inaugurado em 1965, uma das principais praças esportivas do país foi operacionalizada pela Administração de Estádios do Estado de Minas Gerais (ADEMG) ${ }^{2}$, autarquia estadual, durante 45 anos. Em 2010, para realização das reformas e adequações não só do Estádio, mas também do seu entorno, foi assinado um Contrato de Concessão Administrativa, por meio de PPP entre o Estado e a Concessionária Minas Arena Gestão de Instalação Esportiva S.A3. A duração do contrato é de 27 anos com possibilidade de prorrogação.

\footnotetext{
1 De acordo com Cabral e Silva Jr. (2009), além das Parcerias Público-Privadas, temos também às privatizações, concessões e terceirizações como forma de contrato entre o Estado e a iniciativa privada.

2 A ADEMG foi criada em 08 de julho de 1965 e extinta em 27 de dezembro de 2013. Disponível em: https:// leisestaduais.com.br/mg/lei-ordinaria-n-21083-2013-minas-gerais-extingue-a-autarquia-administracao-de-estadiosdo-estado-de-minas-gerais-ademg-e-da-outras-providencias. Acesso em: 10 abr. 2020.

3 Disponível em: http://www.ppp.mg.gov.br/images/documentos/Projetos/concluidos/Mineirao/Contrato\%20PPP\%20 Mineirao.pdf. Acesso em: 12 abr. 2020
} 
Em junho de 2010, o Clube Atlético Mineiro (CAM) realizaria a sua última partida no Mineirão ${ }^{4}$ antes da reforma de adequação do estádio para sediar a Copa do Mundo de Futebol Masculino, realizada no Brasil em 2014. Diante do cenário de transformações que se apresentava, havia preocupações de parte dos torcedores e da mídia especializada relacionadas não somente com a arquitetura e a engenharia do Estádio, mas também o temor de não poderem saborear o tradicional "Tropeiro do Mineirão" (prato típico da culinária de Minas Gerais e que era consumido em larga escala pelo público presente aos jogos) $)^{5}$.

O "tropeirão", como é carinhosamente chamado pelos torcedores, é comercializado no Mineirão desde a sua inauguração, nas lanchonetes localizadas nos setores do estádio. Dentre elas, a mais famosa ficava no Bar 13, de concessão da família Elvina de Oliveira, que cozinhava no local havia 33 anos a convite de Dona Lola, sua hoje falecida irmã e primeira proprietária do recinto. Dona Vina, como é conhecida pelos frequentadores, foi a primeira a adicionar ao tradicional prato o molho de tomate e o ovo frito por cima do bife, que se consolidaram como características marcantes do "tropeirão".

Durante o período de reforma do Mineirão, no qual o Atlético realizou grande parte dos jogos no Estádio Joaquim Henrique Nogueira, conhecido como Arena do Jacaré, localizado na cidade de Sete Lagoas - MG, o prato continuou sendo servido na "casa" provisória, distante $65 \mathrm{~km}$ da capital. Já o Tropeirão do bar 13 foi deslocado e fixou moradia em Belo Horizonte, no bairro Itapoã, na região da Pampulha, a aproximadamente $6 \mathrm{~km}$ do Mineirão.

Durante ao menos os próximos vinte e cinco anos contados a partir de 2013, o estádio será administrado pela empresa Minas Arena que garante manter as tradições do estádio junto a novas opções de alimentação. Dizia-se que o número de bares diminuiria de 38 para 28 (MANNA, 2011) e havia rumores de que grandes redes do setor alimentício assumiriam uma parcela considerável desses pontos.

Pois bem, a reabertura do Mineirão ocorreu no início de 2013. Foi naquele período - da reinauguração do estádio até o ano de 2015 - que o Grupo de Estudos sobre Futebol e Torcidas (GEFuT/UFMG) desenvolveu uma pesquisa que se propôs a investigar e analisar as percepções e manifestações dos torcedores frequentadores do "Novo Mineirão", buscando conhecer as impressões iniciais de torcedores presentes nos jogos sobre as modificações estruturais do estádio, além de suas expectativas em relação ao funcionamento do mesmo e à conduta dos torcedores.

Naquela pesquisa, intitulada "Percepções e manifestações do torcedor sobre o ‘Novo Mineirão', foram aplicados questionários com perguntas abertas e fechadas a torcedores e torcedoras. Suplementando os dados dos questionários, observações

4 O Estádio Governador Magalhães Pinto está localizado no bairro São Luiz, na região da Pampulha e se configura como a principal praça futebolística do Estado de Minas Gerais.

5 Naquela época, tal insatisfação era notória entre torcedores atleticanos e cruzeirenses. Essa inferência é possível a partir de comentários de torcedores e da mídia especializada que circulavam em 2013. No momento de confecção deste artigo ainda era possível constatar o afirmado através das seguintes reportagens: "Novo tropeiro do Mineirão é alvo de reclamações" exibida no Programa Balanço Geral, da emissora de televisão Rede Record. Disponível em: https://www.youtube.com/watch?v=U9-XanBXuio. Acesso em: 20 maio 2020); e "Apesar de protestos, tropeiro continuará servido em 'versão resumida' no Mineirão" publicada no Superesportes (jornal Estado de Minas). Disponível em https://www.mg.superesportes.com.br/app/noticias/especiais/novo-mineirao/1,653,1,10/2013/02/26/ noticia_cruzeiro, 243403/apesar-de-protestos-tropeiro-seguira-servido-em-versao-resumida-no-mineirao.shtml. Acesso em: 20 maio 2020. 
no ambiente das arquibancadas e de seus frequentadores foram realizadas. A equipe de coleta e observação era composta por quatro a oito pesquisadores por partida, distribuídos pelos diversos setores do estádio ${ }^{6}$. A dinâmica de trabalho consistia em chegar ao local com duas horas de antecedência do horário marcado para a partida e terminar a coleta 30 minutos antes do início dos jogos. Os questionários eram aplicados aos torcedores e torcedoras em idade acima de 18 anos, sentados nas cadeiras da arquibancada.

Embora os torcedores tenham sido selecionados pela abertura para aproximação percebida pelos pesquisadores, estes tinham como referência a proporção de sete homens adultos, três mulheres, três idosos acima de 60 anos e duas pessoas com deficiência (PCDs). Esse critério foi extraído das orientações passadas pelo extinto Ministério do Esporte (com base em dados do IBGE sobre o público que frequentava estádios de futebol) para pesquisa sobre o Estatuto de Defesa do Torcedor realizada no mesmo estádio, anteriormente à reforma (NICÁCIO et al., 2009). Dessa maneira, foi uma preocupação dos pesquisadores e pesquisadoras incluir entre os participantes pessoas com deficiência ${ }^{7}$, mulheres (visivelmente em menor número em todos os jogos), idosos e integrantes de torcidas organizadas (homens e mulheres presentes em diversos setores). Após a coleta, os dados foram tabulados utilizando-se o software Statistical Package for Social Sciences (SPSS IBM) e analisados pelos pesquisadores envolvidos.

O presente artigo é um recorte da pesquisa mais abrangente realizada pelo GEFuT e está fundamentado na coleta, tabulação e análise de 266 questionários aplicados em 10 partidas $^{8}$ do CAM entre os anos de 2013 e $2015^{9}$. Nesse sentido, procura-se evidenciar as perspectivas dos torcedores e torcedoras sobre mudanças na alimentação e sociabilidade decorrentes da reforma do Estádio ${ }^{10}$. Para tal o texto foi circunscrito em três momentos.

O primeiro tem como proposta a construção do perfil torcedor do CAM presente no Mineirão através das seguintes variáveis: gênero ${ }^{11}$, idade, estado civil, escolaridade, ocupação profissional, renda e local de residência. A análise do perfil é apresentada para compreender os discursos sobre alimentação e sociabilidade dentro e nos arredores do estádio emergentes a partir dos questionários e das observações realizadas. O segundo momento apresenta a associação entre comida, identidade e pertença para evidenciar a perspectiva dos participantes da pesquisa sobre o "tropeirão" e suas mudanças. No terceiro momento, a percepção sobre a retirada dos barraqueiros do entorno do Estádio e a transformação das formas de

6 Os questionários foram aplicados em todos os setores do estádio a exceção dos camarotes, pois não havia permissão para realizar a pesquisa junto aos presentes nesses espaços.

7 A proporção da PCDs indicada não foi atingida, pois, em alguns setores e jogos não foi possível encontrá-los no estádio.

8 Jogos válidos pelas seguintes competições: Campeonato Mineiro e Taça Libertadores da América de 2013, Copa do Brasil e Recopa Sul-americana, em 2014, e o Campeonato Brasileiro de 2015. Na época da reabertura do Mineirão, o Atlético já havia firmado contrato de parceria de 25 anos com a empresa administradora da Arena Independência, motivo pelo qual passou a jogar suas partidas prioritariamente no Independência em comparação ao Mineirão.

9 O total de público pagante no Mineirão nesses dez jogos foi de 468.513 pessoas, sendo a média de público de 46.851 pessoas por partida. Jogo com maior público - Atlético x Olímpia, Libertadores 2013 (56.557). Jogo com menor público - Atlético x Chapecoense, Campeonato Brasileiro 2015 (32.229).

10 Ressalta-se que, embora a pesquisa tenha se realizado em jogos do Cruzeiro Esporte Clube, Clube Atlético Mineiro e América Futebol Clube, analisamos neste artigo apenas os questionários dos jogos do Atlético como mandante no Mineirão.

11 A maioria homens por conta do critério de seleção dos participantes. 
vivência social entre os torcedores é abordada. Nessas duas últimas partes do texto evidencia-se uma tensão entre ordem e desordem, aprovação e desaprovação, no que diz respeito as mudanças a retirada de um ingrediente do tropeiro e da retirada das barracas do entorno do estádio.

\section{QUEM FREQUENTA O “NOVO” MINEIRÃO?}

De que maneira podem ser apresentadas as pessoas que frequentavam o Mineirão e estavam presentes nos jogos do CAM ocorridos nos anos de 2013, 2014 e 2015? Na tabulação dos dados coletados, aparte a predeterminação da participação de homens $(76 \%)$ e mulheres $(24 \%)$. Verificou-se que esses torcedores e torcedoras estão na faixa etária entre 20 e 39 anos (50\% do total), não deficientes físicos (95,5\%) e não participantes de torcidas organizadas (95,9\%), predominando o estado civil casado $(51,5 \%)$. Além disso, essas pessoas não eram nem estudantes $(78,2 \%)$ e nem aposentadas (93,2\%), sendo $25,9 \%$ dessas pessoas clientes de programa sócio-torcedor e $73,3 \%$ não.

Em relação à escolaridade, verificou-se que quase metade dos indivíduos tinha o ensino médio completo (43,61\%), seguido por uma quantidade significativa de pessoas com graduação $(28,95 \%)$ e pós-graduação $(18,80 \%)$ completas. A maioria desses indivíduos possuíam alguma ocupação profissional $(83,1 \%)$.

O gráfico a seguir ilustra a renda dos pesquisados.

Figura 1 - Renda mensal dos participantes da pesquisa

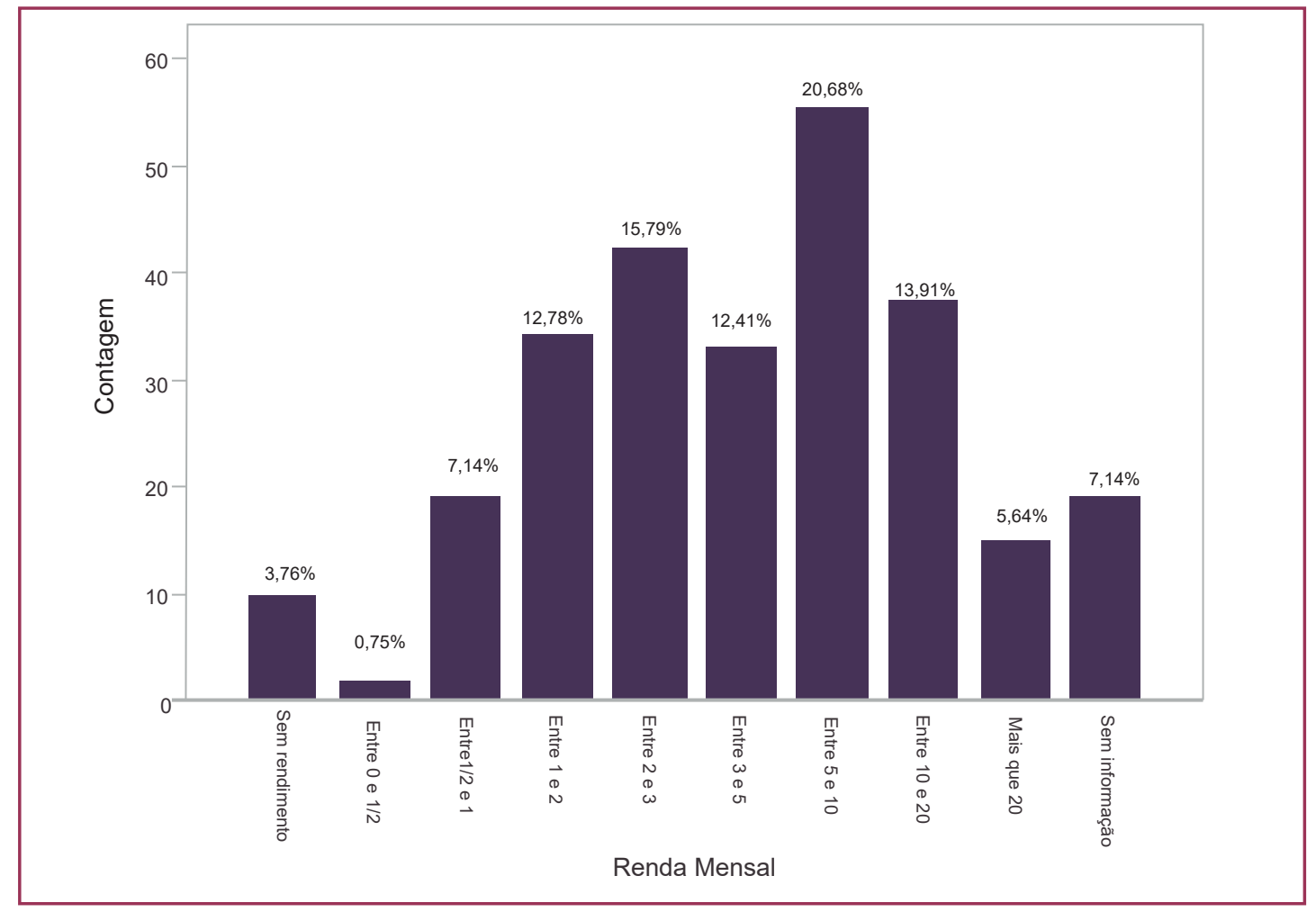

Fonte: elaborada pelos autores através do software SPSS.

Em relação à renda, nota-se que 20,6\% auferem entre cinco e dez salários mínimos por mês, sendo essa faixa de salário a com maior número de torcedores. 
Porém, considera-se importante ressaltar que a porcentagem entre as faixas de um até cinco salários mínimos é que compõe a maioria de torcedores (40,98\%), em empate técnico com os que ganham mais de cinco salários em diante $(40,23 \%)$. Pequena é a quantidade de torcedores que recebem menos de um salário por mês $(11,65 \%)$.

Figura 2 - distribuição do local de moradia dos torcedores pelas Regionais Administrativa de Belo Horizonte.

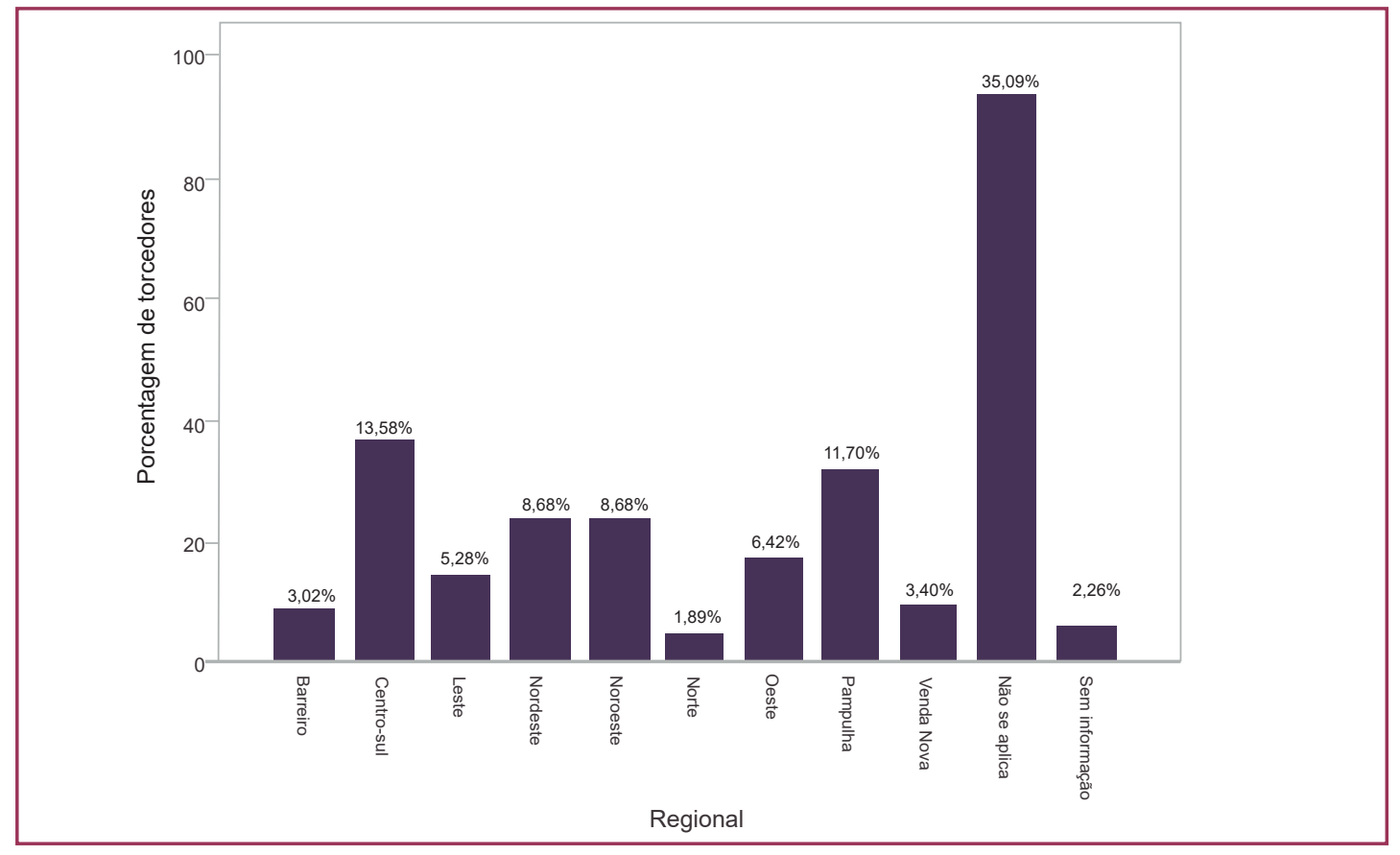

Fonte: elaborada pelos autores através do software SPSS.

Dos torcedores e torcedoras entrevistados, $65 \%$ residiam em Belo Horizonte e $35 \%$ residiam em outras cidades. Ao limitar esses dados por local de moradia dentro de Belo Horizonte verificou-se que a regional administrativa com a maioria de torcedores presentes é a Centro-Sul (13,58\%), seguida da regional Pampulha $(11,70 \%)$ onde está localizado o Mineirão. É importante ressaltar que as regionais Centro-Sul e Pampulha são, respectivamente, as regionais de Belo Horizonte com o maior índice de desenvolvimento humano no município (IDHM). Elas são as que concentram os maiores índices de renda e grau de escolaridade (PNUD, 2010) ${ }^{12}$. Os entrevistados de outras regionais, embora em número menor, somam juntos $17,2 \%$ dos torcedores e torcedoras. Esse é o caso da regional Nordeste (8,6\%) e Noroeste (8,6\%).

A partir desses dados, pode-se afirmar que, entre homens e mulheres participantes da pesquisa, o perfil correspondia a maioria de adultos, casados, das classes B e C (segundo classificação do IBGE), com graduação completa, não sócios-torcedores e não torcedores organizados, moradores das regionais CentroSul e Pampulha. Percebe-se também que o público pesquisado tem alto grau de escolaridade, possui ocupação profissional e recebe rendimentos de médios a altos.

É partindo da percepção desses torcedores que pensa-se as transformações na alimentação e formas de sociabilidade do "novo" Mineirão.

12 O Índice desenvolvido pelo Programa das Nações Unidas para o Desenvolvimento (PNUD) é composto de indicadores de três dimensões do desenvolvimento humano: longevidade, educação e renda. $\mathrm{O}$ índice varia de 0 a 1 e, quanto mais próximo de 1, maior o desenvolvimento humano. Disponível em: https://prefeitura.pbh.gov.br/ estatisticas-e-indicadores/indice-de-desenvolvimento-humano-municipal-de-belo-horizonte. Acesso em: 5 out. 2019. 


\section{COMIDA DE ESTÁDIO: O “TROPEIRÃO” DO MINEIRÃO}

Sabe-se que os alimentos consumidos durante o período de assistência nos estádios faz parte da experiência dos torcedores com o espetáculo. É isso que ensinam Gaffney e Bale (2005), quando abordam as qualidades sensoriais associadas a pratica de assistir jogos nos estádios esportivos: o paladar é um dos sentidos que acompanha a experiência nesses espaços.

Além disso, essa experiência com a alimentação é multideterminada, pois se desdobra em "modalidades sensoriais diversas: gustativas, tátil, olfativa, proprioceptiva, térmica" (LE BRETON, 2016, p.377). Dos cinco sentidos essenciais à experiência humana, quatro são estimulados pelo contato com a comida: a visão, o olfato, o paladar e o tato. Mas isso não é tudo, os sabores são impregnados de afetividade e de memória, como indicam Le Breton (2016) e De Certeau, Giard e Mayol (2013). Afetividade na socialização do gosto que é aprendido na relação com o outro, com o grupo a que se pertence e memória de sabores, odores e cores dos alimentos sorvidos na infância. Uma completa nutrição do corpo e da alma. Uma incorporação, tanto real quanto simbólica, do que alguém é, da sua identidade e do seu pertencimento social (FISCHLER, 1988; CAPLAN, 2003).

A aproximação entre comida e identidade - sentimentos de pertença e afetividade - não são estranhos à compreensão da cultura brasileira. Rial (2005) argumenta que o tema da alimentação é central para a estruturação de uma identidade brasileira. Ao explorar os primeiros relatos sobre alimentação no Brasil a autora se depara com ambiguidades nos relatos que ora se detém sobre a fartura, ora para escassez da mesa brasileira. Abundância e carência nutricional que indicam como os brasileiros se relacionam com a comida e como, através delas, estruturam suas próprias relações sociais. É nesse sentido que DaMatta (1997) compreende o comer e a comida como um idioma que revela, através de seus códigos e desdobramentos, as relações na sociedade brasileira. Para esse autor a culinária brasileira é relacional, situacional, hierárquica, marcada por formas intermediárias de preparo de pratos, e também um ato que conjuga a coletividade e a individualidade.

A culinária brasileira também é impactada pela estrutura social. Portanto, a comida e o comer refletem a sociedade e se desdobram revelando questões sobre hierarquias, moralidades, sexualidades (DAMATTA, 1997), gênero e idade (MACIEL, 1996), distinções sociais e gostos culinários (BOURDIEU, 2007), classificações sociais e estigmas (MACIEL, 2005), política, dominação e opressão racial (FRY, 1982; 2001), regionalidades, localidades e globalização (MORAIS, 2004; MATIAS; MASCARENHAS, 2008). É nesse sentido que se propõe a pensar o tropeiro no estádio.

Feijão, farinha de mandioca, pedaços de carne de sol e toucinho de porco. Essa era a base alimentar das tropas: grupos de homens que atravessavam Minas Gerais transportando mercadorias por todo o Brasil no período colonial. A mistura desses ingredientes caracteriza o tradicional feijão tropeiro, assim intitulado por conta de suas origens. É preciso reafirmar que o tropeiro já não é necessariamente preparado com os mesmos ingredientes de outrora. De versões mais simples às mais requintadas, variações da receita e dos modos de preparo podem ser encontradas 
Brasil afora, pois como indicam Matias e Mascarenhas (2008) sua composição é híbrida, fruto da movimentação dos Tropeiros e da importância histórico-econômica do movimento desses comerciantes durante os séculos XVIII e XIX.

No entanto, como argumenta Morais (2004) o feijão tropeiro foi apropriado como uma característica a culinária mineira. A autora o identifica como o símbolo maior da mineiridade e revela o discurso de construção, através de livros de culinária, de uma tradição inventada para reforçar uma comunidade inventada nos moldes que entendem respectivamente Hobsbawn (2008) e Anderson (2008). Por tudo que foi mencionado até o momento, a aproximação entre comida e a vivência torcedora permite pensar as transformações do "novo" Mineirão na perspectiva de seus usuários. Nessa "tradição inventada" até mesmo o futebol mineiro possui sua versão da comida: o Tropeirão do Mineirão.

Nesse sentido, os dados coletados com os torcedores do CAM em dias de jogo assemelham-se aos dados de Campos (2016). Essa autora, ao estudar o uso e apropriação do Estádio após a reforma enfocando a torcida do Cruzeiro Esporte Clube, identificou muitas insatisfações com a comida (qualidade do tropeiro) e com a retirada dos barraqueiros (que está relacionada com a socialização, como veremos, mas também com a comida e a bebida).

Apresentando a opinião dos torcedores e torcedoras pesquisados, o gráfico a seguir mostra a percepção de atleticanos e atleticanas em relação às modificações do tropeiro que passou a ser servido no estádio após a reforma.

Figura 3- Opinião de torcedores sobre o tropeiro do "Novo Mineirão"

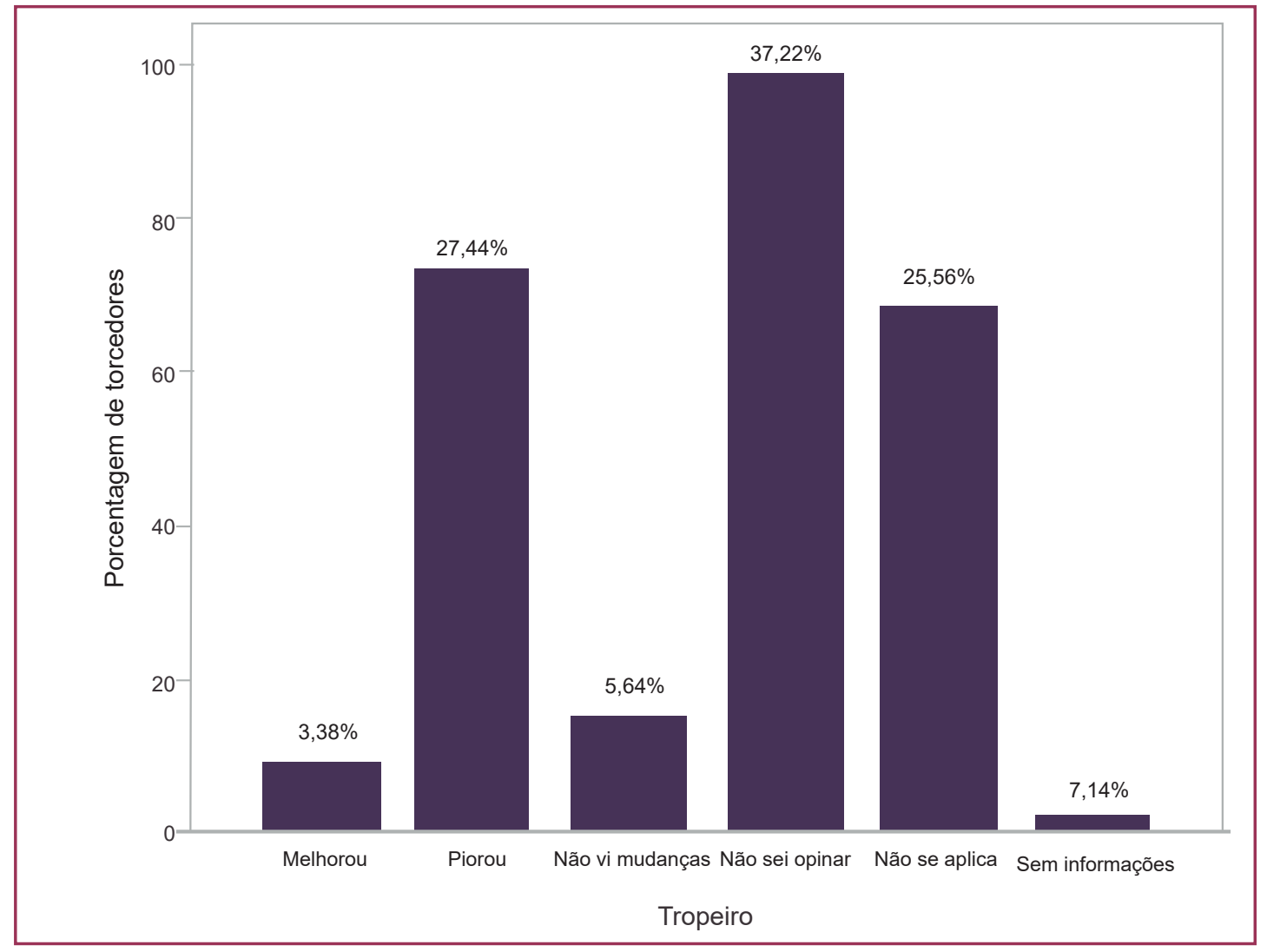

Fonte: elaborada pelos autores através do software SPSS. 
Apesar das rivalidades campais, torcedores de Atlético e Cruzeiro têm perspectivas semelhantes em relação à experiência de alimentação dentro e nos arredores do estádio. Não é nossa intenção desvendar toda a complexidade da sociabilidade no estádio, e dos torcedores que o frequentam, através do tropeiro. De certo nos faltariam elementos para tal. Mas, através das mudanças na preparação do prato e na sua forma de apresentação e na reação e respostas dos torcedores ao serem perguntados sobre sua opinião de satisfação com o prato, levantamos indícios sobre essa experiência. $\mathrm{Na}$ amostra de Campos (2016), 23\% dos entrevistados reclamaram da alimentação, $11,5 \%$ dos entrevistados da qualidade do tropeiro e $30 \%$ sentem falta do antigo tropeiro.

$\mathrm{Na}$ coleta de dados com os torcedores do CAM, nota-se que, embora grande parte dos torcedores e torcedoras não tenham sabido opinar ou não tenham respondido à pergunta ${ }^{13}$, não é de se ignorar que, entre os que tinham algo a dizer sobre as mudanças no tropeiro, $27,44 \%$ indicaram que a qualidade do mesmo piorou. Apenas $3,38 \%$ acharam que melhorou e $5,64 \%$ não viram mudanças. Além disso, o preço dos alimentos dentro do estádio foi entendido como abusivo por $59 \%$ dos entrevistados.

O tropeiro piorou foi à resposta típica do torcedor que percebeu a diferença: "Tropeiro muito ruim, falta muita coisa no tropeiro" (21/04/2013 Atlético x Vila Nova - homem, casado, microempresário do entretenimento). Assim pode-se pensar que o tropeiro piorou para quem comia o tropeiro no "antigo" Mineirão e a porcentagem reflete essa comparação entre um antes e um depois para quem já frequentava o Estádio antes da reforma. E a nova experiência indica uma série de insatisfações, como a ausência de ovo, da quantidade das porções, na forma de servir a comida no prato (antes de plástico, passando a ser de isopor).

No estádio, mais do que uma receita, o feijão tropeiro é um símbolo constante no imaginário do torcedor mineiro. É publicamente reconhecido como patrimônio cultural para seus frequentadores. Em dias de jogos; antes, durante ou depois das partidas; nas lanchonetes internas ou com os vendedores ambulantes nos arredores do estádio; por todos os lados e dentre outros alimentos, o feijão tropeiro está presente.

O Tropeirão do Mineirão vinha acompanhado por uma camada de arroz, couve, torresmo, um bife de lombo de porco, um ovo frito e molho caseiro com pequenos pedaços de tomate:

O tropeirão do [bar] 13 desafiava as leis da gravidade, da arquitetura e do bom-senso. A caprichadíssima porção, minuciosamente empilhada no pratinho de plástico, exigia do torcedor esfomeado talentos de equilibrista. O plástico pelando de quente, que queimava as mãos, aumentava o desafio. Passando a torre de comida de uma mão para a outra, se espremendo entre corpos suarentos, o torcedor tinha de chegar intacto ao seu lugar na arquibancada. Acomodado, tinha que abordar o bifão de pernil com uma singela colherinha de plástico. O colo servia de mesa para o pantagruélico acepipe, mas uma explosão por perto, de euforia ou ódio, poderia ser fatal. Se houvesse um gol, valia tudo: feijão-tropeiro virava confete e couve, serpentina (MANNA, 2011, p.1).

13 Tais situações aconteciam quando o torcedor ou torcedora não havia experimentado alguma das duas versões do tropeiro. 
Acrescenta-se à descrição do jornalista mineiro Nunno Manna um importante detalhe: não somente o fino prato era de plástico, como também o eram os talheres - no caso, a colher -, o que poderia tornar-se um elemento desafiador para os torcedores menos treinados, sendo obrigados a improvisar, naqueles momentos, estratégias para levar o generoso bife à boca. Não por acaso, muitos escolhiam o horário do intervalo ou os momentos antecedentes à partida para saborear o Tropeirão sem perder um lance do jogo.

No novo Mineirão, a retirada do ovo foi justificada por uma questão de custos com a higiene alimentar (CAMPOS, 2016). Como prevê a Lei $n^{\circ} 6.437$ de 20 de agosto de 1977, em seu artigo número dois, parágrafo um e incisos I, II e III, as infrações sanitárias podem variar de dois mil reais até um milhão e quinhentos mil reais dependendo da gravidade (BRASIL, 1977). A justificativa econômica para retirar o ovo do "tropeirão do Mineirão", baseada em uma norma sanitária, aparentemente segue um código do sistema simbólico técnico cientifico que parece contemplar um novo perfil de consumidor.

Marins, Araújo e Jacob (2011), ao abordar as estratégias publicitárias em relação aos alimentos, evidenciam novas percepções em relação a escolha alimentar pelos consumidores. Elas identificam um novo perfil de consumidor:

\begin{abstract}
Um novo perfil de consumidores, preocupados coma estreita relação alimentação-saúde-doença, vem exigindo das indústrias alimentícias novas estratégias de mercado [...] A vida moderna, associada ao desenvolvimento de novas tecnologias aplicadas a áreas de alimentos, impulsionou o aumento do consumo de produtos industrializados. Por outro lado, as indústrias de alimento investem cada vez mais recursos de propagandas em seus produtos, com o objetivo de conquistar novos e fieis consumidores. Neste contexto, com um mercado em expansão, surge também um novo perfil de consumo, o novo consumidor deseja alimentos equilibrados do ponto de vista nutricional, de fácil preparo e sensorialmente atraentes. (MARINS; ARAÚJO; JACOB, 2011, p. 3874).
\end{abstract}

As autoras não tratam do novo consumidor nas novas arenas de futebol. O contexto delas é outro. No entanto, é possível pensar que esse novo perfil de consumidor também esteja nos estádios e não está alijado dessas novas percepções alimentares.

Nesse sentido, pode-se pensar que a retirada do ovo ${ }^{14}$ também revele uma nova ordem alimentar refletida num novo público que se pretendia conquistar. Esse novo público tem o tropeiro servido em um novo recipiente - antes um prato de papel e agora uma marmita de alumínio -, com uma quantidade de comida menor - antes era um prato que era bem servido assemelhando-se ao formato do pico de uma montanha e agora se assemelha a uma planície -, com um preço pouco acessível. Dessas mudanças pode-se realizar as seguintes conjecturas: uma em relação a identidade e ao pertencimento, e outra em relação a etiqueta dos modos de consumir o tropeiro.

Seguindo a perspectiva proposta por Morais (2004), de que o tropeiro é o símbolo maior da mineiridade, pode-se pensar que a ausência do ovo, reclamação fundamental dos torcedores em relação ao novo prato na época da pesquisa, remeta

14 O ovo retornaria ao prato servido no Mineirão no ano de 2016 seguindo as novas regras de segurança alimentar em seu preparo. 
a um incômodo em relação à comida que concedia uma sensação de unidade de pertencimento. Algo que se aproxima do que Fischler (1988) aponta como um problema de "distúrbio de identidade alimentar". Embora o termo faça parecer que mudanças na tradição sejam patologias, algo que não endossamos, nos interessa o ponto em que o que está em jogo não é somente o rompimento de uma ordem alimentar, mas, sobretudo, a pretensão da imposição de uma nova ordem dentro dos estádios. Certamente o tropeiro recebeu vários acréscimos de ingredientes além do feijão, farinha e toucinho (linguiça, ovo, couve) sem torná-lo estranho para o grupo que o estava consumindo (MORAIS, 2004). Contudo, a retirada de ingredientes e a combinação de outros ingredientes alheios ao sistema culinário do tropeiro modificaram-no, causando estranhamento em parte de seus consumidores.

$\mathrm{Na}$ argumentação proposta por Elias (1990), as transformações das maneiras a mesa, reflexo do maior autocontrole dos comportamentos e emoções, modificou a estrutura da sociedade e o balanço de poder entre as classes em épocas passadas. Assim, quanto mais prestigio e poder político, econômico e social, maior o refreamento das emoções e comportamentos nas interações entre os grupos dominantes numa determinada configuração social. Portanto, menor o ímpeto violento e maior o comedimento.

Nem paixões violentas e muito menos glutonaria desenfreada são permitidas para determinadas classes sociais. É isso que revela Mennel (1987) ao dialogar com Elias (1990) e acrescentar a questão de ingestão de comida como uma evidência do processo civilizatório. Para esse autor, quanto maior o comedimento em relação ao montante de ingestão de comida (e consequentemente menor massa corporal) e maior o refinamento dos gostos (e consequentemente um acréscimo econômico para consumi-lo), maior será a distinção de um grupo perante o outro.

É para essa transformação que os torcedores apontam quando reclamam do tropeiro. Uma nova ordem alimentar que pode ser traduzida pelas falas torcedoras como uma elitização ${ }^{15}$ dos costumes e uma exclusão do público, mesmo que imaginado, associado ao "velho" Mineirão: "Ficou muito Gourmet. Ficou mais caro. Tirou o direito do pobre de torcer" (29/07/2015, Atlético X São Paulo - homem, solteiro, estudante). "Onze conto no tropeiro é abusivo" (13/08/2015 Atlético x Grêmio - homem, 30 anos, casado, líder de produção).

Outro dado relevante da pesquisa que pode indicar essa percepção de uma nova ordem alimentar é a porcentagem dos que não souberam opinar sobre as mudanças no tropeiro. Os $37,2 \%$ de torcedores que se inserem nessa categoria possivelmente estão iniciando a experiência de ver jogos depois da reforma e não possuem parâmetros para a comparação. Ou então não consumiam o tropeiro anteriormente. Podem ser pessoas receosas em comer alimentos fora de casa, pois não sabem a procedência do alimento ou que entendem que "o asseio dos bares" melhorou (28/06/2015, Atlético x Lanus - homem, 61 anos, divorciado, microempresário). Poucos foram os que indicaram não sentir mudanças significativas no gosto do prato, pois, como vimos anteriormente, o tropeiro é fundamental no

15 Intenção de elitização essa que acompanha também o aumento de quase $200 \%$ no preço médio dos ingressos após a reabertura do Mineirão, conforme constatou Queiroz (2019). 
discurso da mineiridade. A associação entre a identidade mineira e o feijão tropeiro dá contornos ao pertencimento dessa comunidade regional.

\section{RELAÇÕES DE SOCIABILIDADE E AS BARRACAS DO ENTORNO}

As mudanças dentro do Estádio também foram percebidas nos seus arredores. O entorno do Mineirão era um espaço marcado pela presença de vendedores de comidas e bebidas em suas barracas. Não somente os alimentos sofreram alterações, mas também o modo como os torcedores agregavam-se antes das partidas.

Nesse sentido, a retirada dos barraqueiros do entorno do "Mineirão" foi percebida como uma fonte de insatisfação para os torcedores durante a pesquisa. Nesse aspecto os dados coletados entre os torcedores do CAM também são similares ao de Campos $(2016)^{16}$.

O gráfico a seguir ilustra a opinião de torcedores e torcedoras sobre a retirada dos barraqueiros do entorno do Mineirão.

Figura 4 - Opinião sobre a retirada dos barraqueiros do entorno

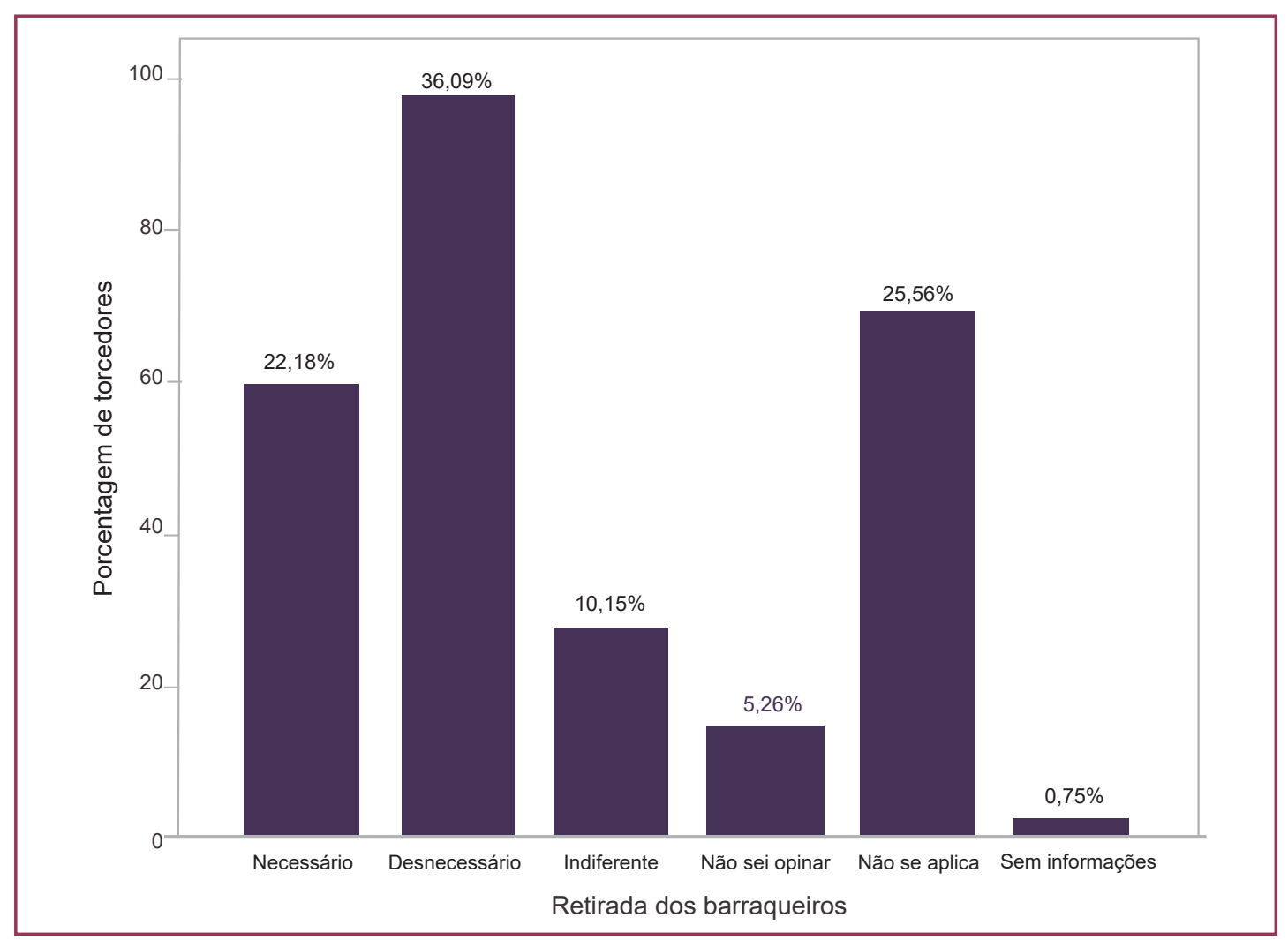

Fonte: elaborada pelos autores através do software SPSS.

Dos torcedores entrevistados, $36,1 \%$ indicaram que a retirada dos barraqueiros no entorno do Mineirão, no período pesquisado, foi desnecessária. Ao passo que $22,2 \%$ acharam necessária a retirada dos barraqueiros ${ }^{17}$.

16 Os dados de Campos (2016), sobre os torcedores cruzeirenses, indicam $23,3 \%$ dos torcedores sentem falta dos barraqueiros que ocupavam as mediações antes da reforma.

17 Novamente, os torcedores e torcedoras que não souberam opinar ou aos quais a pergunta não se aplicava corresponde aos que não frequentavam o Mineirão anteriormente ou que não viveram a experiência no entorno do Mineirão antes da reforma por algum outro motivo. 
Os que não concordavam à época com a retirada dos barraqueiros justificaram sua resposta apelando para a sensibilidade e empatia com os trabalhadores que iriam perder seus meios de subsistência ${ }^{18}$. Um torcedor explicou: "Desnecessário a retirada dos barraqueiros. Se legalizasse era melhor. (Era uma) oportunidade de trabalho". (28/06/2015, Atlético x Joinville - homem, 20 anos, solteiro, analista).

A presença dos barraqueiros foi defendida por torcedores que enfatizaram as relações de sociabilidade e ponto de encontro com amigos. O encontro nas barracas nos arredores do Mineirão pode ser pensando com uma forma de sociação em que a comida e a bebida são mediadores das conversas.

Simmel (1983) identifica a sociabilidade como uma forma pura de sociação na medida em que as pessoas envolvidas na interação formam uma unidade. Essa unidade é construída por interesses comuns, no caso aqui analisado, o futebol, onde a forma que toma a interação é mais importante do que o conteúdo: ou seja, é uma atividade desinteressada a qual a conversa se dá entre iguais, nessa perspectiva. Uma atividade democrática de troca que se basta por si mesma. Portanto, na relação de sociabilidade, o que está em jogo é o prazer de se estar junto e compartilhar experiências coletivas, mesmo que efêmeras. Um momento para não se fazer nada importante a não ser socializar.

É para essas relações de sociabilidade que indicam as narrativas dos torcedores em relação às barraquinhas: "Gosto de comprar as coisas. Ficar bebendo e conversando" (15/10/2014 - Atlético x Corinthians - mulher, 49 anos, casada, comerciante). "Era um atrativo a mais, local de encontro com os amigos mesmo em setores diferentes" (13/08/2015 - Atlético x Grêmio - homem, 35 anos, casado, autônomo). Mas isso não é tudo, sabe-se que o alimento e a bebida que se partilha, em coletividade, afirma a humanidade e seu pertencimento grupal e, suplementa os laços sociais (MINTZ; DU BOIS, 2002 e MINTZ, 1996). Mintz (2001), ao realizar uma breve revisão da associação entre antropologia e comida, reforça a ideia de que a comida representa a identidade e o pertencimento social e nos faz humanos. Ele argumenta: "O comportamento relativo à comida liga-se diretamente ao sentido de nós mesmos e a nossa identidade social, e isso parece valer para todos os seres humanos" (MINTZ, 2001, p. 31). Mas não somente o que se come junto, mas também o que se bebe junto define uma identidade e pertencimento social. É isso que revela Douglas (2010, p.8): "Drinks also act as markers of personal identity and of boundaries of inclusion and exclusion"19.

Pode-se afirmar que, para esses autores e autoras, beber e comer junto com "os seus", sejam esses familiares, amigos e/ou conhecidos, sintetiza a experiência de socialização (desinteressada). É essa socialização que a retirada dos barraqueiros no entorno do Mineirão perturba. É na ausência desse contexto relacional que é possível compreender a insatisfação de parte dos torcedores naquele período.

\footnotetext{
18 Interessante notar que, embora os barraqueiros tenham sido retirados do entrono do estádio, outros atores surgiram para substituí-los: as vans (veículo em forma de caixa com quatro rodas) que comercializam os mesmos tipos de alimentos que os barraqueiros comercializavam antes da reforma (macarrão na chapa, cachorro quente, churrasquinho e, claro, o tropeiro). A dúvida que permanece é se há antigos barraqueiros entre esses novos atores. Sabemos que a Associação dos Baraqueiros do Entorno do Mineirão (ABAEM), criada para responder à retirada dos barraqueiros, continua ativa nove anos após o fechamento do estádio para as reformas.

19 "Beber também opera como um marcador de identidade pessoal e de fronteiras de inclusão e exclusão" (Tradução nossa).
} 
Acrescenta-se que as barracas eram vivenciadas como um espaço de tradição e de rotina, local de preço acessível do alimento e variedade de opções de comida. "Fazia parte da tradição do estádio" (15/10/2014 - Atlético x Corinthians - homem, 35 anos, casado, funcionário público). "O legal era o clima de reunião nas barraquinhas antes do jogo. Era tradição" (15/10/2014 - Atlético x Corinthians - mulher, 41 anos, divorciada, professora).

Os torcedores que acharam necessária a retirada dos barraqueiros destacaram dúvidas sobre a procedência do alimento consumido do lado de fora do estádio. A higiene alimentar foi levantada como uma justificativa para o rigoroso controle dos barraqueiros: "higiene e segurança alimentar" (29/07/2015 - Atlético x São Paulo homem, 54 anos, casado, bancário).

Nessas falas há uma preocupação com a higiene em relação a comida servida na rua pelos barraqueiros. Como argumentam Cardoso, Santos e Silva (2009) esta preocupação é legitima no sentido em que uma das características marcantes da comida de rua é a improvisação e desconsiderações de requisitos sanitários básicos. E, nesse contexto,

Ressalta-se que o setor de comida de rua envolve muito trabalho informal, baixo nível de tecnologia, investimento mínimo de capital e limitado conhecimento sobre higiene, existindo para muitos vendedores a simples transferência do preparo doméstico de alimentos para o preparo em espaços públicos (CARDOSO; SANTOS; SILVA, 2009, p.1221).

No entanto, essa preocupação pode indicar uma renovação parcial de torcedores, como indicamos em outro momento desse artigo. Isso porque, e é importante ressaltar, antes da reforma não havia essa distinção entre comida de fora e de dentro do Estádio. Não havia essa distinção, em relação ao alimento no espaço público consumido fora e no alimento consumido dentro do Mineirão ${ }^{20}$.

Em certo sentido, essa preocupação com a limpeza e higiene foi refletida em outras esferas que ultrapassam a questão da alimentação ${ }^{21}$. A preocupação com a movimentação do público e, consequentemente, o melhor aproveitamento do espaço de circulação, foram fatores que levaram alguns torcedores a concordarem com a retirada dos barraqueiros. Ademais, a poluição visual seria um fator que desagradava aos torcedores favoráveis à retirada das barracas.

Nessa perspectiva, a estética do "novo" Mineirão parecia "maculada" pela presença das barracas ao seu redor. As barracas multicoloridas formam uma desordem, uma dissonância que ao serem colocadas lado a lado com a representação de ordem e harmonia de um estádio reformado nos moldes dos padrões europeus precisam ser excluídas do espaço e da visão dos torcedores e torcedoras. Tal qual a transformação da ordem alimentar, a transformação da ordem espacial projeta a expectativa de um 
perfil de torcedor. Um torcedor mais propenso a realizar julgamentos em relação à estética visual do espaço e mais exigente com a qualidade da comida, no comer fora de casa e higiene, na quantidade da comida e no modo de servi-la.

\section{CONSIDERAÇÕES FINAIS}

A percepção que a maioria dos estádios brasileiros são instalações esportivas antigas, cujas estruturas físicas foram dimensionadas para um contexto diferente e menos complexo, em termos de necessidade de segurança, daquele encontrado atualmente nos eventos esportivos que sediam jogos importantes, é um argumento compartilhado por autores como Ensslin, Ensslin e Pacheco (2012) e Lages et al. (2015).

Nesse cenário, o antigo Mineirão, antes das mudanças da última reforma até então, recebia críticas de ser pouco seguro, como também pouco confortável e, além disso, não fornecia serviços de qualidade. Em contraposição a essa perspectiva, o "novo Mineirão" seria um equipamento urbano de fundamental importância para a melhoria da qualidade da fruição, mobilidade, estética e agregação torcedora. Portanto um novo espaço atrativo para um público parcialmente renovado. Verificamos que os torcedores e torcedoras participantes da pesquisa apresentavam, em sua maioria, alto grau de escolaridade, empregabilidade e rendimentos médios, além de grande parte deles ser proveniente de regiões de Belo Horizonte com alto IDHM. Ademais esses torcedores, não eram, na sua maioria, membros de torcidas organizadas e nem possuíam planos de sócio-torcedor (modalidade esta que se expandiu nos últimos anos).

Tendo em conta que a afirmação pode ser arriscada e que necessita de mais pesquisas para ser melhor compreendida, percebe-se indícios de uma renovação parcial dos torcedores do Atlético presentes no Mineirão naqueles anos iniciais após reforma. Os dados coletados indicam que o perfil do frequentador do estádio estivesse se transformando naquele período, mas não em sua totalidade. É preciso também levar em conta que o Mineirão deixou de ser a principal "casa" do CAM naqueles anos e a indignação de parte da torcida com o Estádio pós-reforma era notória nas arquibancadas e anéis superiores do estádio durante a aplicação dos questionários. Nesse sentido, alguns torcedores e algumas torcedoras manifestaram satisfação com as mudanças do "novo Mineirão", outros e outras foram críticos e se mostraram receosos com as transformações, sobretudo no que se refere a interferência em tradições e costumes dos torcedores, explicitando que não bastaria a ordem do Poder Público e da empresa administradora do Estádio para mudar os costumes e tradições, principalmente os relacionados à alimentação e sociabilidade. Além disso, esse artigo evidenciou que duas transformações chamaram a atenção dos torcedores e torcedoras entre os anos de 2013 e 2015 em relação aos dois últimos pontos citados. Uma delas se deu no modo de preparo, de servir, de quantidade e qualidade do tropeiro ${ }^{22}$, comida típica do estádio Mineirão que contribuía para atribuir

22 Mesmo que a percepção torcedora seja ambígua e marcada por uma tensão entre a saudação da mudança e o saudosismo da tradição, pensa-se que Bourdieu (2007) permite realizar essa associação entre a transformação do perfil dos torcedores e mudanças nos comportamentos relativos a alimentação. Este autor indica que, "Assim, na classe dominante, pode-se distinguir simplificando, três estruturas de consumo distribuídas em três itens principais: alimentação, cultura e despesas com a apresentação de si e representação (vestuário, cuidados de beleza, artigos de higiene, pessoal de serviço)" (BOURDIEU 2007, p. 174). 
a identidade e construir o pertencimento dos torcedores, sejam eles ou elas de qualquer agremiação, com o espaço de lazer e fruição de sua paixão.

A ausência de um dos ingredientes do prato, mais especificamente o ovo frito, naqueles primeiros anos, significou a ruptura da familiaridade do paladar e, consequentemente, da experiência que compunha a totalidade do espetáculo. Tanto que, diante dos questionamentos, a empresa administradora do estádio reviu sua estrutura para comportar estufas que possibilitassem o retorno do ovo frito seguindo as normas da vigilância sanitária. Nesse sentido, a transformação pode ser percebida como uma importante alteração do prato, do pertencimento e do tradicional prazer gustativo. Havia uma tensão entre a ordem previamente conhecida e o discurso de modernidade do "novo" espaço de lazer. Sem consulta aos frequentadores, o consórcio Minas Arena elaborou uma nova lógica de comensalidade legitimada pela higiene e pelo cuidado com a saúde coletiva que a princípio não levou em conta os desejos dos torcedores

Outro ponto dessa transformação se deu fora do estádio. O momento de reunião, de sociação que marcava o tempo antes e depois da partida e as aproximações afetivas entre conhecidos e desconhecidos, sofreu rupturas em nome da estética e da higiene. As barracas multicoloridas, as bebidas e comidas (com preços módicos) são tomadas, por alguns, como a síntese da desordem e do mal gosto que é iminente afastar dos olhares mais disciplinados e civilizados nessa nova ordem que se pretendia instaurar. Para alguns, não importa se algumas pessoas que compunham aquele ambiente eram parte da experiência de lazer. Menos importante ainda se outras tinham naquele espaço o meio de ganhar a vida. Entre os que foram destituídos de seus encontros, afetividades e prazeres, e aqueles que foram destituídos de seus meios de sobrevivência financeira, se posicionam os possuidores e instituidores de uma "nova" experiência do torcer. Apesar da intenção de se atrair um novo público, o Mineirão segue como território em disputa também através dos hábitos e regulações alimentares e da ocupação dos espaços dentro e fora do estádio nos dias de jogos.

\section{REFERÊNCIAS}

ANDERSON, Benedict. Comunidades imaginadas: reflexões sobre a origem e a difusão do nacionalismo. São Paulo: Companhia das Letras, 2008.

BRASIL. Lei n. ${ }^{\circ} 6.437$, de 20 de agosto de 1977. Configura infrações à legislação sanitária federal, estabelece as sanções respectivas, e dá outras providências. Disponível em: http:// www.planalto.gov.br/ccivil 03/LEIS/L6437.htm\#art40. Acesso: 19 abr. 2020.

BOTTA, Charles R; DELMONT, Ron; REDDY, Ruben. Recomendações e Requisitos Técnicos para Estádios de Futebol. 5. ed. 2011. Disponível em: http://docplayer.com. br/5064228-5a-edicao-2011-estadios-de-futebol-recomendacoes-e-requisit GAVINI ostecnicos-p.html. Acesso em: 15 abr. 2020

BOURDIEU, Pierre. A Distinção: crítica social do julgamento. São Paulo: EDUSP; Porto Alegre: Zouk, 2007. 
CABRAL, Sandro; SILVA JÚNIOR, Antônio Francisco. PPPs e decisões de investimento na construção de estádios de futebol. O\&S, v.16, n.48, p.39-58, jan./mar. 2009.

CAMPOS, Priscila Augusta Ferreira. As formas de uso e apropriação do estádio Mineirão após a reforma. 2016. 313 f. Tese (Doutorado em Educação Física) - Faculdade de Educação Física, Universidade Estadual de Campinas, Campinas, 2016.

CAPLAN, Pat. Food, health and identity. London: Routledge; New York: Taylor \& Francis e- Library, 2003.

CARDOSO, Ryzia de Cassia Vieira; SANTOS, Sandra Maria Chaves dos; SILVA, Edileuza Oliveira. Comida de rua e intervenção: estratégias e propostas para o mundo em movimento. Ciência \& Saúde Coletiva. v.14, n.4, p. 1215-1224, 2009. Disponível em: http:// www.scielo.br/scielo.php?script=sci arttext\&pid=S1413-81232009000400027. Acesso em: 14 abr. 2020.

DAMATTA, Roberto. O que faz o brasil, Brasil? Rio de Janeiro: Rocco, 1997.

DE CERTEAU, Michel; GIARD, Luce; MAYOL, Pierre. A invenção do cotidiano 2: morar, cozinhar. Petrópolis, RJ: Vozes, 2013.

DOUGLAS, Mary. Pureza e perigo. Lisboa: Edições 70, 1991.

DOUGLAS, Mary. Constructive drinking: perspectives on drink from anthropology. London: Routledge/ Taylor \& Francis, 2010.

ELIAS, Norbert. O processo civilizador: uma história dos costumes. Rio de Janeiro: Jorge Zahar, 1990.

ENSSLIN, Leonardo; ENSSLIN, Sandra Rolim; PACHECO, Giovanni Cardoso. Um estudo sobre segurança em estádios de futebol baseado na análise bibliométrica da literatura internacional. Perspectivas em Ciência da Informação, v.17, n.2, p.71-91, abr./jun. 2012.

FISCHLER, Claude. Food, self and identity. Social Science Information, v. 2, n.27, p. 275292, 1988. Disponível em: http://gen.lib.rus.ec/scimag/10.1177\%2F053901888027002005. Acesso em: 5 maio 2019.

FRY, Peter. Feijoada e "soul food": notas sobre a manipulação de símbolos étnicos e nacionais. In: FRY, Peter. Para inglês ver: identidade e política na cultura brasileira. Rio de Janeiro: Jorge Zahar, 1982. p.47-53.

FRY, Peter. Feijoada e soul food 25 anos depois. In: ESTERCI, Neide; FRY, Peter; GOLDENBERG, Mirian. Fazendo Antropologia no Brasil. Rio de Janeiro: DP\&A, 2001. p.35-56.

GAFFNEY, Chris and BALE, John. Sensing the stadium. In: VERTINSKY, Patrícia; BALE, John. Sites of sport: space, place, experience. London: Routledge; New York: Taylor \& Francis e- Library, 2005. p. 25-39.

HOBSBAWN, Eric. Introdução: a invenção das tradições. In: HOBSBAWN, Eric; RANGER, Terence. A invenção das tradições. Rio de Janeiro: Paz e Terra, 2008. p. 9-24.

LAGES, Carlos Eduardo Munaier; SILVA, Silvio Ricardo da; SILVA, Luciano Pereira; MASCARENHAS, Fernando. A Copa do Mundo de futebol em Belo Horizonte-MG: impactos e legados. Motrivivência, v. 27, n. 44, p. 79-92, maio 2015.

LE BRETON, David. Antropologia dos sentidos. Petrópolis, RJ: Vozes, 2016. 
MACIEL, Maria Eunice. Churrasco à Gaúcha. Horizontes Antropológicos, Ano 2, n.4, p.34-48, jan./jun. 1996.

MACIEL, Maria Eunice. Identidade cultural e alimentação. In: CANESQUI, Ana Maria; GARCIA, Rosa Vanda Diez. Antropologia e Nutrição: um diálogo possível. Rio de Janeiro: FIOCRUZ, 2005. p.49-56.

MANNA, Nuno. Patrimônio ameaçado: a reforma do Mineirão põe em risco o tropeirão. Piauí, ano 5, n. 56, 2011. Disponível em: https://piaui.folha.uol.com.br/materia/ patrimonio-ameacadol. Acesso em: 08 abr. 2019.

MARINS, Bianca Ramos; ARAÚJO, Inesita Soares de; JACOB, Silvana do Couto. A propaganda dos alimentos: orientação ou apenas estímulo ao consumo? Ciências \& Saúde Coletiva. v. 16, n. 9, p. 3873-3882, 2011. Disponível em: http://www.scielo.br/scielo. php?script=sci_arttext\&pid=S1413-81232011001000023. Acesso em: 15 abr. 2020.

MATIAS, Lindon Fonseca; MASCARENHAS, Rúbia Gisele Tramontin. Culinária Tropeira e suas potencialidades no turismo dos campos gerais do Paraná: uma análise dos Municípios de Castro, Lapa e Tibai. CULTUR: Revista de cultura e turismo, ano 2, n. 2, p. 18-46, jul. 2008.

MENNEL, Stephen. On the civilizing appetite. Theory, Culture \& Society, v.4, n.2, p. 373403, 1987. Disponível em: http://gen.lib.rus.ec/scimag/10.1177\%2F026327687004002011. Acesso em: 5 maio 2019.

MINNAERT, Ana Cláudia de Sá Teles; FREITAS, Maria do Carmo Soares. Práticas higiênicas em uma feira livre da cidade de Salvador (BA). Ciências \& Saúde Coletiva, n.15 (supl.1), p. 1607-1614, 2010. Disponível em: http://www.scielo.br/scielo.php?pid=S1413

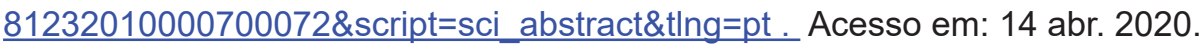

MINTZ, Sidney. Food for Thought: an interview with Sidney Mintz. Anthropology Newsletter, v. 37, n. 8, p. 3-4, 1996. Disponível em: http://gen.lib.rus.ecl scimag/10.1111\%2Fan.1996.37.8.1.2. Acesso em: 5 maio 2019.

MINTZ, Sidney. Comida e antropologia: uma breve revisão. Revista Brasileira de Ciências Sociais. v. 16, n. 47, p. 31-41, 2001. Disponível em: http://www.scielo.br/pdf/rbcsoc/ v16n47/7718.pdf. Acesso em: 15 abr. 2020.

MINTZ, Sidney; DU BOIS, Christine. The anthropology of food and eating. Annual Review of Anthropology. v. 31, p. 99-119, 2002. Disponível em: http://gen.lib.rus.ec/ scimag/10.2307\%2F4132873 Acesso em: 05 maio 2019.

MORAIS, Luciana Patrícia. Culinária típica e identidade regional: a expressão de processos de construção, reprodução e reinvenção da mineiridade em livros e restaurantes de comida mineira. 2004. 154 f. Dissertação (Mestre em História) - Faculdade de Filosofia e Ciências Humanas/Departamento de Pós-Graduação em História, Universidade Federal de Minas Gerais, Belo Horizonte, 2004.

NICÁCIO, Luiz; SANTANA, Thiago José Silva; GOMES, André; ABRANTES, Felipe; SILVA, Silvio Ricardo da. Campeonato Brasileiro de 2007: A Relação do torcedor de futebol com o estatuto de defesa do torcedor na cidade de Belo Horizonte (MG). Revista Brasileira Ciências do Esporte, v. 30, n. 2, p. 25-38, jan. 2009.

QUEIROZ, Felipe Pereira de. O preço da emoção: as transformações no custo do lazer futebolístico no estádio Mineirão entre 1994 e 2018. Dissertação (Mestrado em Estudos do Lazer) - Escola de Educação Física, Fisioterapia e Terapia Ocupacional, Programa de PósGraduação em Estudos do Lazer, Universidade Federal de Minas Gerais, Belo Horizonte, 2019. 
REIS, Cláudio José Oliveira; CABRAL, Sandro; Parcerias público-privadas (PPP) em megaeventos esportivos: um estudo comparativo da provisão de arenas esportivas para a Copa do Mundo Fifa Brasil 2014. Revista de Administração Pública, v.4, n.51, p.551-579, jul./ago. 2017.

RIAL, Carmem da Silva. Brasil: primeiros estudos sobre comida e identidade. In: CANESQUI, Ana Maria; GARCIA, Rosa Vanda Diez. Antropologia e Nutrição: um diálogo possível. Rio de Janeiro: FIOCRUZ, 2005. p. 86-100.

SIMMEL, George. Sociabilidade - um exemplo de sociologia pura e formal. In: MORAES FILHO, Evaristo de. George Simmel. Sociologia. São Paulo: Ática, 1983. p. 165-181. 
Abstract: This article looks into changes in food and sociability habits at the "new" Mineirão Arena from the perspective of 266 Atlético Mineiro's fans. It used field research with questionnaires and observations made at the bleachers to provide a brief analysis of the profile of the audience that attended the Mineirão Stadium in 2013-2015. Fans' speech showed some discomfort with the changes in food and the social experiences that were part of whole football match spectacle. As for fans' profiles, a high degree of education and employability was observed, and they used to live in places with high Human Development Indices (HDI). This scenario provided new insights into the appearance of urban equipment and food hygiene, indicating a space of dispute on food both inside and outside the stadium, as well as other changes in fans' sociability.

Keywords: Soccer. Leisure activities. Social change. Sports and recreational facilities.

Resumen: Este artículo analiza los cambios en la alimentación y las formas de sociabilidad en el "nuevo" Estadio Mineirão, desde la perspectiva de 266 aficionados del Clube Atlético Mineiro. Además, presenta un breve análisis del perfil del público que asistió al Estadio Mineirão entre 2013 y 2015. Es el resultado de una investigación de campo donde se aplicaron cuestionarios y se hicieron observaciones en el ambiente de las gradas. Se observó, en el discurso de los aficionados, incomodidad con los cambios en la alimentación y en las experiencias que conformaron la totalidad del espectáculo. En cuanto al perfil de los aficionados, se observó un alto nivel de escolaridad y empleabilidad, además de que residen en locales con alto Índice de Desarrollo Humano Municipal. Este escenario trajo consigo nuevas percepciones sobre la apariencia del equipamiento urbano y la higiene de los alimentos, mostrando un espacio de disputas por la alimentación dentro y fuera del estadio y otros cambios en la sociabilidad de los aficionados.

Palabras clave: Fútbol. Activities recreativas. Cambio social. Instalaciones deportivas y recreativas. 


\section{LICENÇA DE USO}

Este é um artigo publicado em acesso aberto (Open Access) sob a licença Creative Commons atribuição Não Comercial 4.0 (CC BY-NC 4.0), que permite uso, distribuição e reprodução em qualquer meio, desde que o trabalho original seja corretamente citado, com a restrição que impede o uso para fins comerciais. Mais informações em: http://creativecommons.org/licenses/by-nc/4.0

\section{CONFLITO DE INTERESSES}

Os autores declararam que não há conflito de interesses neste trabalho.

\section{CONTRIBUIÇÕES AUTORAIS}

Leonardo Turchi Pacheco participou da pesquisa, escrita e análise do manuscrito. Marina de Mattos Dantas participou da pesquisa, escrita e análise do manuscrito. Adriano Lopes de Souza participou da pesquisa, escrita e análise do manuscrito. Silvio Ricardo da Silva participou da pesquisa, escrita e análise do manuscrito.

\section{FINANCIAMENTO}

O presente trabalho foi realizado sem nenhum apoio financeiro.

\section{COMO REFERENCIAR}

PACHECO, Leonardo Turchi; Dantas, Marina de Mattos; SOUZA Adriano Lopes de; SILVA, Silvio Ricardo da. Comida de estádio: reflexões sobre o "tropeirão" e a sociabilidade no "Novo Mineirão". Movimento, v. 26, p. e26052, jan./dez. 2020. Disponível em: https://www.seer.ufrgs.br/Movimento/article/view/98224. Acesso em: 22 jul. 2020. DOI: https://doi.org/10.22456/1982-8918.98224.

\section{RESPONSÁVEIS EDITORIAIS}

Alex Branco Fraga*, Elisandro Schultz Wittizorecki, Ivone Job*, Mauro Myskiw*, Raquel da Silveira*

*Universidade Federal do Rio Grande do Sul, Escola de Educação Física, Fisioterapia e Dança, Porto Alegre, RS, Brasil 